\title{
Odors Detected by Mice Deficient in Cyclic Nucleotide-Gated Channel Subunit A2 Stimulate the Main Olfactory System
}

\author{
Weihong Lin, ${ }^{1}$ Julie Arellano, ${ }^{1}$ Burton Slotnick, ${ }^{2}$ and Diego Restrepo ${ }^{1}$ \\ ${ }^{1}$ Department of Cell and Developmental Biology, Neuroscience Program and Rocky Mountain Taste and Smell Center, University of Colorado Health \\ Sciences Center, Denver, Colorado 80262, and 2Department of Psychology, University of South Florida, Tampa, Florida 33620
}

\begin{abstract}
It is believed that odor transduction in the mammalian main olfactory system only involves the cAMP-signaling pathway. Here, we report on odor responsiveness in mice with a disrupted cyclic nucleotide-gated (CNG) channel subunit A2. Several odorants, including putative pheromones, can be detected and discriminated by these mice behaviorally. These odors elicit responses in the olfactory epithelium, main olfactory bulb, and olfactory (piriform) cortex of CNGA2 knock-out mice. In addition, responses to odors detected by CNGA2 knock-out mice are relatively insensitive to inhibitors of the cAMP pathway. These results provide strong evidence that cAMP-independent pathways in the main olfactory system of mammals participate in detecting a subset of odors.
\end{abstract}

Key words: cAMP; olfactory; transduction; operant; cyclic GMP; odor

\section{Introduction}

Binding of odorants to olfactory receptors activates the cAMPsignaling pathway resulting in depolarization of olfactory receptor neurons (ORNs) in the main olfactory epithelium (Schild and Restrepo, 1998; Gold, 1999; Zufall and Munger, 2001). Targeted disruption of elements of the cAMP pathway, including the cyclic nucleotide-gated channel subunit A2 (CNGA2) (Brunet et al., 1996; Zhao and Reed, 2001), the G-protein $G_{\text {olf }}$ (Belluscio et al., 1998), or adenylyl cyclase III (ACIII) (Wong et al., 2000; Trinh and Storm, 2003), result in loss of odorant-evoked electroolfactogram (EOG) responses to a variety of odorants. Together with other pharmacological and physiological studies, these results have been taken to imply that the cAMP pathway is the only transduction mechanism in the main olfactory epithelium (MOE) of mammals (Schild and Restrepo, 1998; Gold, 1999; Zufall and Munger, 2001; Trinh and Storm, 2003). However, some ORNs in the MOE of mammals do not express the elements of the CAMP pathway and have been postulated to respond to odors through the cyclic GMP (cGMP) pathway (Baker et al., 1999; Zufall and Munger, 2001; Dulac and Torello, 2003), and alternate signaling pathways appear to play an important role in olfactory responses in a variety of species (Restrepo et al., 1990; Ache and Zhainazarov, 1995; Manzini and Schild, 2003). Whether alternate transduction pathways are active in mammals is an important question, because the existence of different path-

Received Jan. 18, 2004; revised Feb. 22, 2004; accepted Feb. 23, 2004.

This work was supported by National Institutes of Health Grants DC00566, DC04657, DC006070 (D.R.), DC0043 (W.L.), and MH6118 (B.S.).We thank Drs. Tom Finger, Sue Kinnamon, Tatsuya Ogura, and Michele Schaefer for discussion, Audrey Hathaway for technical assistance, Dr. William Cain for assistance with estimation of air concentration of odorants, Drs. John Ngai and Randall Reed for providing us with knock-out mice, and Dr. Gene Delay for help on the initial phase of the behavioral experiments and discussion.

Correspondence should be addressed to Dr. Diego Restrepo, Department of Cell and Developmental Biology, Neuroscience Program and Rocky Mountain Taste and Smell Center, University of Colorado Health Sciences Center, Room 4505 School of Medicine, 4200 East 9th Avenue, Denver, C0 80262. E-mail: Diego.Restrepo@uchsc.edu.

DOI:10.1523/JNEUROSCI.0188-04.2004

Copyright $\odot 2004$ Society for Neuroscience $\quad$ 0270-6474/04/243703-08\$15.00/0 ways could result in more sophisticated processing at the peripheral level (Ache and Zhainazarov, 1995), and because alternate transduction pathways in the MOE could subserve different behaviors. Here, we report that a subset of odorants that can be detected by CNGA2 knock-out (KO) mice stimulate the main olfactory system (MOS). Our study provides compelling evidence that alternate signal transduction pathways participate in detection of odors in the MOE of mammals.

\section{Materials and Methods}

Animals

Adult FVB and 129 mice were purchased from the Jackson Laboratory (Bar Harbor, ME). Adult male CNGA2 knock-out mice and their wildtype littermates were offspring produced by backcrossing the heterozygous CNGA2 knock-out female mice (Brunet et al., 1996) (kindly provided by Dr. John Ngai, University of California, Berkely, CA) with wildtype FVB male mice. We also obtained CNGA2-green fluorescent protein (GFP) knock-out mice kindly provided by Dr. Randall Reed (Johns Hopkins University, Baltimore, MD). In these mice, the coding region for CNGA2 has been replaced with the coding region for a GFP (Zhao and Reed, 2001). Heterozygous female CNGA2-GFP mice were backcrossed with 129 mice. Both types of CNGA2 knock-out mice were unable to detect lilial in the operant conditioning task and detected ethyl acetate (EA), 2,5-dimethyl pyrazine (DMP), and 2-heptanone. PCR or Southern blot analyses for the absence of the deleted CNG channel and presence of neomycin resistance gene or GFP determined their genotypes.

The original publication by Brunet et al. (1996) reported a failure to thrive for male CNGA2 knock-out hemizygous mice, presumably because of the lack of chemosensory cues important for lactation. Although initially it was difficult for us to raise CNGA2 knock-out mice to adulthood, we found that judicious thinning of the litter, fostering of the pups, or use of wet solid food at weaning can be used to obtain adult knock-out mice (Baker et al., 1999). After weaning, the mice gained weight quickly and by 2 months of age, and with a few exceptions, CNGA2 knock-out mice could not be distinguished from their littermates on the basis of weight. Mice used in this study were older than 2 months of age.

Bulbectomies were performed under ketamine-xylazine $(100 \mu \mathrm{g} /$ gm-20 $\mu \mathrm{g} / \mathrm{gm}$ body weight) anesthesia as detailed by DellaCorte et al. 
(1996). All procedures were performed under protocols approved by the University of Colorado Health Sciences Center Animal Care and Use Committee.

\section{Odorants and other chemicals}

Odorants were obtained from Aldrich Chemical Company (Milwaukee, WI), Fluka (Ronkon Koma, NY), or Takasago Corporation (Shinagawa, Japan). Odorants were made freshly by dilution with vigorous vortexing and sonication into either odorless mineral oil (for behavioral experiments; Rite-Aid Corporation, Harrisburg, PA) or Ringer's saline (for EOG recordings) (in mM: $145 \mathrm{NaCl}, 5 \mathrm{KCl}, 20 \mathrm{HEPES}, 1 \mathrm{MgCl}_{2}, 1 \mathrm{CaCl}_{2}$, $1 \mathrm{Na}$ pyruvate, and $5 \mathrm{D}$-glucose, $\mathrm{pH}$ 7.2). The AC activator forskolin and the AC inhibitors 9-(tetrahydro-2-furyl)-adenine (SQ22536) and cis- $\mathrm{N}$ (2-phenylcyclopentyl)-azacyclotridecan-2-imine-hydrochloride (MDL12330A) were purchased from Calbiochem (La Jolla, CA). The CNG channel inhibitor L-cis-diltiazem hydrochloride and the phospholipase C (PLC) inhibitor U73122 and inactive analog U73433 were purchased from Calbiochem.

\section{Behavioral odor detection experiments}

For behavior tests, the olfactometer and operant conditioning methods described by Bodyak and Slotnick (1999) were used. Briefly, mice were trained using water reinforcement to sample a $2.5 \mathrm{sec}$ stimulus presentation and respond by licking a water delivery tube in the presence of an odor ( $\mathrm{S}+$ stimulus) and to inhibit responding in the presence of no odor (odor detection task) or a different odor (odor discrimination task). Odorants were diluted with odorless mineral oil, and the headspace was further diluted 40 times with clean air before being introduced to the mouse odor sampling port. Odor concentrations are stated as percentage dilution $(\mathrm{v} / \mathrm{v})$ in mineral oil. Concentrations of odorants in air for ethyl acetate and 2-heptanone (in ppm) were estimated from gas chromatographic calibrations (GC) (Cometto-Muniz et al., 2003).

\section{Treatment with $\mathrm{ZnSO}_{4}$ and 3-methyl indole}

We destroyed the main olfactory epithelium by syringing each nasal vault with $50 \mu \mathrm{l}$ of $5 \% \mathrm{ZnSO}_{4}$ (McBride et al., 2003) or injections of $300 \mathrm{mg} / \mathrm{kg}$ of the olfactory epithelial toxin 3-methyl indole (3-MI) (Setzer and Slotnick, 1998). As a control, we used anterograde transport of wheat germ agglutinin (WGA)-HRP from olfactory and vomeronasal (VNO) epithelium to the olfactory bulb to assess the extent of the lesions as detailed by McBride et al. (2003).

\section{EOG recordings}

Mice were killed by $\mathrm{CO}_{2}$ inhalation followed by decapitation. The head was split along the midline, and the nasal septum was removed to expose the endoturbinate. The half head was mounted on a recording chamber using the dental adhesive Impregum F (3M-ESPE, Maplewood, MN). Ringer's saline was perfused continuously over the surface of the turbinate. Ringer's and odorants were delivered through a gravity-fed computer-controlled perfusion system with an approximate flow rate of $0.2 \mathrm{ml} / \mathrm{sec}$. Each odorant was presented three times, and the largest response was used for analysis to minimize the effect of cross-adaptation. After stimulation with an odorant, the turbinate was washed with saline for 2 min or until its response to Ringer's solution was back to the basal level recorded at the beginning of the experiment $(<0.1 \mathrm{mV})$. EOG recordings were made using an Axopatch $200 \mathrm{~B}$ amplifier controlled by a personal computer with Axon software (Clampex 8; Axon Instruments, Union City, CA). The recording electrode was filled with $0.9 \%$ agar made in Ringer's saline with $1 \%$ neutral red. The electrode was placed on the apical surface of endoturbinate $\mathrm{IIb}$, and the reference $\mathrm{Ag} / \mathrm{AgCl}$ electrode was connected to bath saline through an agar bridge. The recorded signals were low-pass filtered at $20 \mathrm{~Hz}$, digitized at $500 \mathrm{~Hz}$, and analyzed using the Axon software Clampfit. The turbinates were incubated with $\mathrm{AC}$ and $\mathrm{CNG}$ inhibitors for $15 \mathrm{~min}$ to ensure equilibration across the apical membrane. Because EOG responses decreased by $\sim 50 \%$ during the experiment $(2-4 \mathrm{hr})$, we conducted a time course control. The same sets of stimuli without inhibitors were applied in independent experiments to mimic inhibitor application time and the number of stimulations. The percentage decrease during the time course, calculated as the average of nine independent experiments, was then subtracted from the
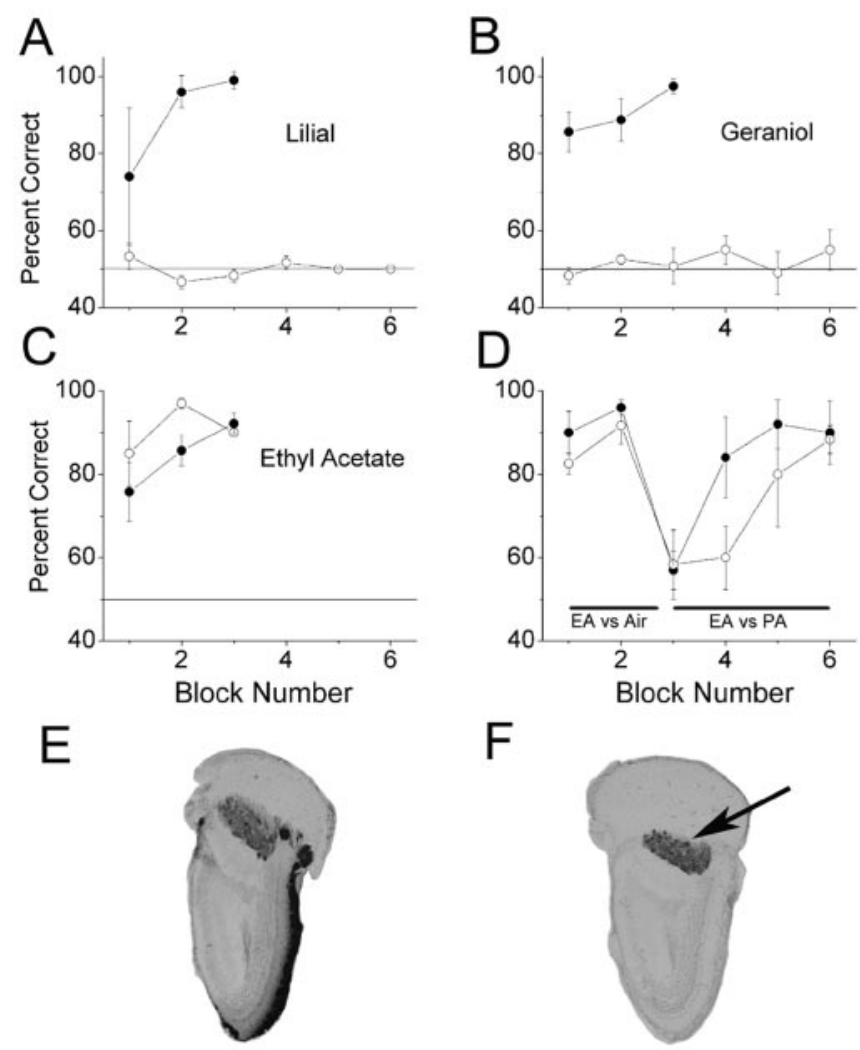

Figure 1. Detection and discrimination tests and innervation in the olfactory bulb in 3-Mltreated mice. $A-C$, Results of odor detection test for CNGA2 knock-out mice and controls ( $S+$ stimulus, odor; $S-$ stimulus, air). The percentage of correct responses is plotted as a function of block number (each block has 20 trials); $50 \%$ represents chance response (horizontal line). Filled circles, Wild-type mice; open circles, CNGA2 knock-out mice. Stimuli were a 1/40 dilution of air equilibrated with $1 \%$ geraniol, $1 \%$ lilial, and $1 \%$ ethyl acetate. Mean \pm SEM ( $n=5-7$ mice each). $D, 0$ dor discrimination test. Mice were water deprived and trained to detect ethyl acetate $(1 / 40$ dilution of $1 \%)$ as the $S+$ stimulus and air as the $S-$ stimulus. In the third block, the $S-$ stimulus was abruptly changed to $1 \%$ propyl acetate (PA). Although the knock-out mice took longer in making the discrimination (ANOVA; $p<0.05$ for phenotype), both CNGA2 knock-outs and controls were able to detect the difference between the two odors (mean $\pm \mathrm{SEM} ; n=5$ ). $E, F$, HRP reactivity in olfactory bulb of control $(E)$ and 3-Ml-treated $(F)$ mice. 3-MI treatment induced denervation of all glomeruli in the main olfactory bulb but did not affect the afferent innervation of the accessory olfactory bulb (arrow).

experiments with inhibitors to calculate the percentage of inhibition resulting from inhibitor application.

\section{Measurement of trigeminal threshold}

Stimulus-induced depression in respiratory rate was used to measure trigeminal thresholds (Schaper, 1993). Respiration was monitored by the change of temperature elicited by air flow through the naris of an anesthetized mouse as monitored with a thermocouple (Omega Engineering, Stamford, CT). Mice were anesthetized with ketamine-xylazine, and the change in voltage drop across the thermocouple was measured using a TDT RP2.1 data acquisition system (Tucker Davis Technologies, Alachua, FL). Mice were stimulated by switching an air stream directed toward the nose flowing at $60 \mathrm{ml} / \mathrm{min}$. Air was saturated with ethyl acetate vapor at different concentrations in air by equilibration with ethyl acetate diluted in mineral oil. The inter-stimulus interval was long enough (2-3 $\mathrm{min})$ to allow full recovery of the decreases in respiration rate elicited by large concentrations of ethyl acetate in air. Data were digitized at $100 \mathrm{~Hz}$ and low-pass filtered at $30 \mathrm{~Hz}$.

\section{Immunodetection of odor-evoked Fos activity}

Ipsilateral naris closure. The surgical procedure was adapted from Baker et al. (1993). Adult wild-type littermates and CNGA2 knock-out mice were anesthetized with ketamine-xylazine (100 $\mu \mathrm{g} / \mathrm{gm}-20 \mu \mathrm{g} / \mathrm{gm}$ body 
Table 1. Behavioral detection of different odors by CNGA2 knock-out mice

\begin{tabular}{|c|c|c|}
\hline Compound & Dilution (1/40) times percentage & Detection \\
\hline DMP & $0.01-1$ & + \\
\hline Ethyl acetate & $5-0.001$ & + \\
\hline Ethyl propionate & $1-0.01$ & + \\
\hline Eugenole & 1 & + \\
\hline 2-Heptanone & 1 & + \\
\hline Octaldehyde & 1 & + \\
\hline 2-Pentanone & 1 & + \\
\hline$N$-Pentyl acetate & $1-0.1$ & + \\
\hline Propyl acetate & 1 & + \\
\hline 2-Butanone & 1 & \pm \\
\hline Citral & 1 & \pm \\
\hline Ethyl benzoate & 0.01 & \pm \\
\hline 2-Heptanone & 0.01 & \pm \\
\hline Isovaleric acid & $1-0.1$ & \pm \\
\hline Kovanol (lyral) & $0.01-1$ & \pm \\
\hline Menthone & 0.01 & \pm \\
\hline 2-0ctanone & 1 & \pm \\
\hline 2-Pentanone & 0.01 & \pm \\
\hline Propyl acetate & 0.01 & \pm \\
\hline Geraniol & 1 & - \\
\hline Lilial & $1-100$ & - \\
\hline Octaldehyde & 0.1 & - \\
\hline $\mathrm{N}$-Pentyl acetate & 0.01 & - \\
\hline
\end{tabular}

+ , CNGA2 knock-out mice were able to detect the stimulus; \pm , some CNGA2 knock-out mice were able to detect the stimulus; - , no CNGA2 knock-out mice were capable of detecting the stimulus. Wild-type littermates could detect all odors. The number of mice tested for each odor ranged from two to eight.

weight). The left or right naris was cauterized (Aaron Medical Industries, St. Petersburg, FL). After surgery, ointment and infant Tylenol were administered to alleviate pain. These mice were killed for experiments $1.5-2$ months after surgery.

Odor exposure. Odor exposure was performed as in our previous $c$-fos mRNA in situ hybridization experiments (Schaefer et al., 2001) with the following modifications. The odor mixture was made freshly by mixing 2-heptanone and DMP (0.5\% each) in $25 \mathrm{ml}$ of mineral oil. Wild-type control or CNGA2 KO mice were placed in a plastic chamber with humidified fresh air continuously flowing at $1950 \mathrm{ml} / \mathrm{min}$. A Matlab (Mathworks, Natick, MA) program controlled the delivery of odorequilibrated air stream at $50 \mathrm{ml} / \mathrm{min}$ to the chamber, producing odor stimulus with 40 times the dilution of the original concentration. Mice were exposed to fresh air in the chamber for $90 \mathrm{~min}$ before being exposed to odorants. Odorant exposure occurred intermittently to minimize adaptation effects. Odors were presented six times for $2 \mathrm{~min}$ with $3 \mathrm{~min}$ intervening fresh air intervals over a $30 \mathrm{~min}$ period.

Tissue preparation and immunolabeling. Mice were anesthetized with ketamine-xylazine $1.5 \mathrm{hr}$ after odor exposure, perfused transcardially with $0.1 \mathrm{M}$ phosphate buffer (PB), followed by a phosphate buffered fixative containing $3 \%$ paraformaldehyde, $0.019 \mathrm{M} \mathrm{L}$-lysine monohydrochloride, and $0.23 \%$ sodium $\mathrm{m}$-periodate. The olfactory bulbs and cerebrum were harvested and postfixed for $2 \mathrm{hr}$ before being transferred into PBS with 25\% sucrose overnight. The tissues were frozen and cut sagittally with a cryostat into free-floating $30 \mu \mathrm{m}$ thick sections. We performed sagittal cuts to maximize the number of glomeruli visualized in medial and lateral sections. Sections were rinsed and incubated in blocking solution containing 2\% normal donkey serum, $0.3 \%$ Triton X-100, and $1 \%$ bovine serum albumin in PBS for $1.5 \mathrm{hr}$.

For single label of Fos protein, the sections were incubated with polyclonal rabbit antibody $(\mathrm{Ab})$ against Fos (Oncogen, Boston, MA) at $1: 10,000$ dilution in the blocking solution $48-72 \mathrm{hr}$ at $4^{\circ} \mathrm{C}$, followed by rinsing and incubation with the biotinylated-sp donkey anti-rabbit secondary Ab (Jackson ImmunoResearch,, West Grove, PA) for $1 \mathrm{hr}$ at room temperature. Sections were then washed and reacted with $\mathrm{ABC}$ kit (Vector Laboratories, Burlingame, CA) for $1.5 \mathrm{hr}$ before being rinsed and reacted with $\mathrm{DAB} / \mathrm{H}_{2} \mathrm{O}_{2}$ solution. Sections were mounted on slides with Fluoromount-G (Fisher Scientific, Pittsburgh, PA).

For double labeling of Fos and phosphodiesterase (PDE2) in CNGA2
A

B

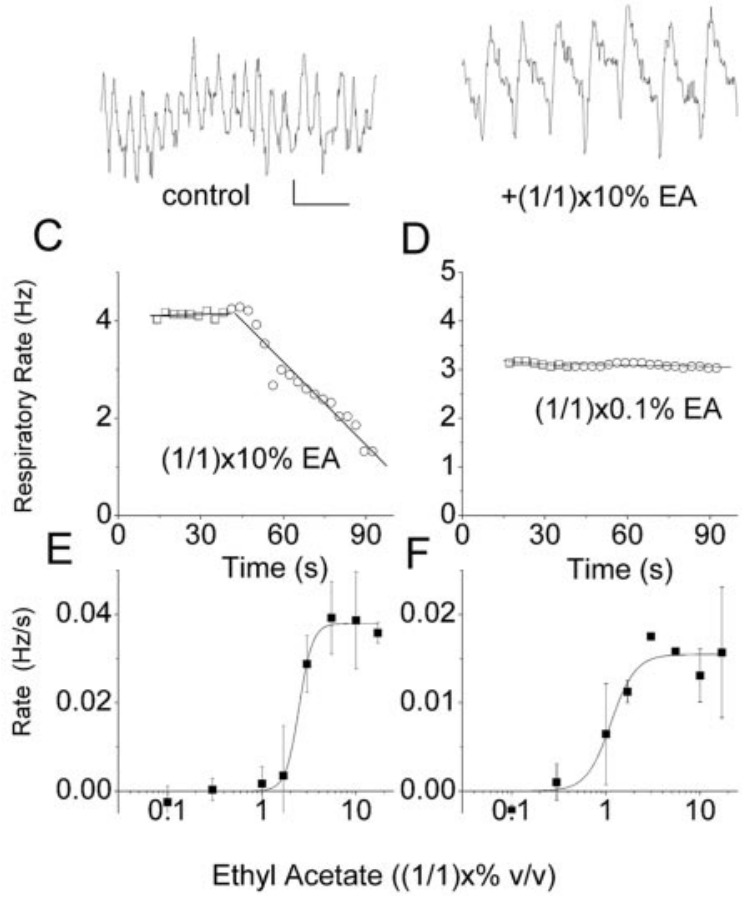

Figure 2. Measurement of differences in trigeminal sensitivity between wild-type and CNGA2 knock-out mice. Trigeminal stimuli elicit a depression of the rate of respiration attributable to a reflex response. Respiration was monitored by recording the changes in voltage in a thermocouple located at the naris of an anesthetized mouse (see Materials and Methods). $A$ and $B$ show the voltage from the thermocouple as a function of time in the absence $(A)$ and presence (B) of air equilibrated with (1/1) $\times 10 \%$ ethyl acetate. Calibration: (in A) $50 \mu \mathrm{V}, 1 \mathrm{sec}$. An increase in temperature produces a decrease in voltage. (and $D$ show the change in respiratory frequency as a function of time before (open squares) and during (open circles) application of $(1 / 1) \times 10 \%(C)$ or $(1 / 1) \times 0.1 \%(D)$ ethyl acetate. Eand $F$ show the absolute value of the rate of change in respiratory frequency as a function of the concentration of ethyl acetate for wildtype $(E)$ and CNGA2 knock-out $(F)$ mice. The $\mathrm{EC}_{50}$ values were 2.5 and $1.1 \%$ ethyl acetate for wild-type and CNGA2 knock-out mice, respectively. Mean \pm SEM ( $n=5$ for wild-type; $n=3$ for CNGA2 knock-out).

KO GFP mice, sections were incubated with antibodies against Fos and polyclonal goat PDE2 (1:100-200; Santa Cruz Biotechnology, Santa Cruz, CA) for more than two nights at $4^{\circ} \mathrm{C}$. Secondary antibodies used were $N, N^{\prime}$-biscarboxypentyl-5, $5^{\prime}$-disulfonatonindodicarbo cyanineconjugated donkey anti-rabbit and Rhodamine Red X-conjugated donkey anti-goat (Jackson ImmunoResearch). For labeling of tyrosine hydroxylase (TH), sections were reacted with the primary Ab (1:2000; Calbiochem) and secondary Ab conjugated with Rhodamine Red X or Alexa 488 (Molecular Probes, Eugene, OR). Removal of primary Ab resulted in no labeling.

Statistics and criteria for counting Fos-positive glomeruli

Kruskal-Wallis ANOVA was used to determine whether there were differences between CNGA2 knock-outs and controls in Figure 3 B, because the field potential changes elicited by odors in the CNGA2 knock-outs were not distributed normally. ANOVA was used to determine whether there were differences within a group in Figure 3 D. A post hoc Tukey's least significance difference procedure was used to test differences between specific treatments. The level of significance was $p<0.05$. Matlab version 6.5 (Mathworks, Natick, MA) was used to perform statistical tests. The criterion used to score Fos-positive glomeruli was developed and validated in previous work in our laboratory (Schaefer et al., 2001). Briefly, glomeruli were scored as positive if a ring of $>180^{\circ}$ of Fos-labeled juxtaglomerular cells surrounded the glomerulus. In addition, and to avoid scoring false-positive glomeruli, we required that Fos-positive glomeruli be found at symmetrical locations in both the left and right olfactory bulb. 


\section{Results}

CNGA2 knock-out mice detect select general odorants and putative pheromones

Consistent with published behavioral experiments with ACIII knock-out mice (Wong et al., 2000), when tested using operant conditioning procedures, the CNGA2 knock-out mice did not detect lilial and geraniol, even at relatively high concentrations (a 40-fold dilution of air equilibrated with $1 \%$ odorant $\mathrm{v} / \mathrm{v}$ in mineral oil $[(1 / 40) \times 1 \%])$ (Fig. $1 A, B)$, and failed to detect even a $1 / 40$ dilution of air equilibrated with undiluted lilial $[(1 / 40) \times$ $100 \%]$. However, the CNGA2 knock-out mice were able to detect $(1 / 40) \times 1 \%$ ethyl acetate (Fig. $1 C$ ) as well as other odorants, including the putative pheromones 2-heptanone and DMP (Table 1).

Mediation by the trigeminal system could be ruled out by our finding that, although trigeminal thresholds of CNGA2 knock-out mice and wild-type mice did not differ substantially (Fig. 2), CNGA2 knockout mice were able to detect $0.2 \mathrm{ppm}$ ethyl acetate $[(1 / 40) \times 0.001 \%]$, more than three orders of magnitude below the trigeminal detection threshold of 600 ppm (Schaper, 1993). In addition, olfactory-bulbectomized mice were not able to detect any odor tested $[(1 / 40) \times 1 \%$ ethyl acetate, $(1 / 40) \times 1 \%$ geraniol, $(1 / 40) \times 1 \% \mathrm{DMP},(1 / 40) \times 1 \%$ isovaleric acid), although they could detect a known trigeminal stimulus (ammonia; data not shown). In addition, CNGA2 knock-out mice were able to discriminate between two closely related odorants (ethyl acetate and propyl acetate), a task that the trigeminal system is not expected to perform (Fig. 1D). Thus, the trigeminal system is not involved in response at these odor concentrations in CNGA2 knock-out mice.

To determine whether the MOS is involved in the detection of ethyl acetate, we destroyed the MOE by syringing each nasal vault with $50 \mu \mathrm{l}$ of $5 \% \mathrm{ZnSO}_{4}$ or by injections of $300 \mathrm{mg} / \mathrm{kg}$ of the olfactory epithelial toxin 3-MI. Anterograde transport of WGA-HRP from olfactory and VNO epithelium to the olfactory bulb was used to assess the extent of the lesions. Neither treatment had a discernable effect on axonal transport from the VNO to the accessory olfactory bulb, but both completely blocked transport to all glomeruli in the main olfactory bulb (MOB) (Fig. 1, compare $E$ and $F$ ) for the first $4-8 \mathrm{~d}$ after treatment. Mice trained to detect $(1 / 40) \times 5 \%$ ethyl acetate before treatment with either $\mathrm{ZnSO}_{4}(n=6)$ or 3 -MI $(n=4)$ performed at chance in daily 100 trial post-treatment tests in our olfactometer, and their ability to detect EA gradually increased only after the first $8-10 \mathrm{~d}$ (data not shown).
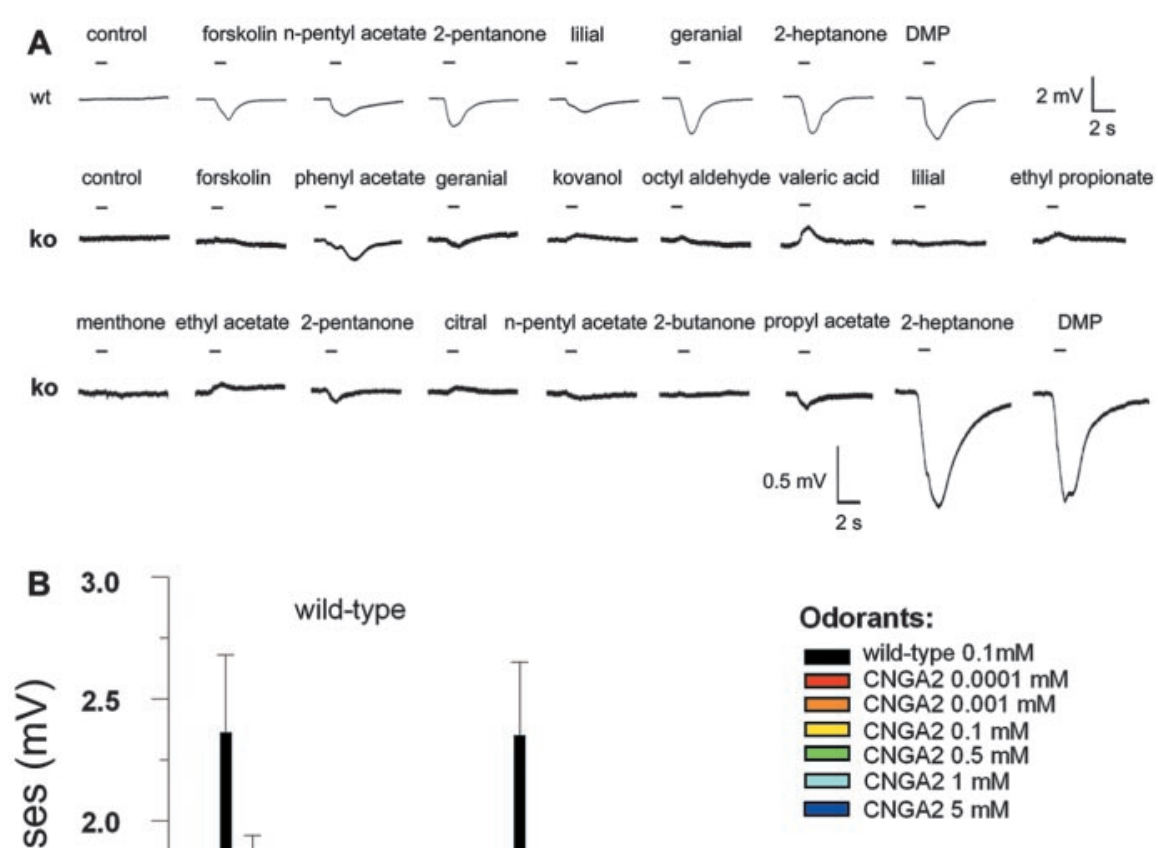

knockout
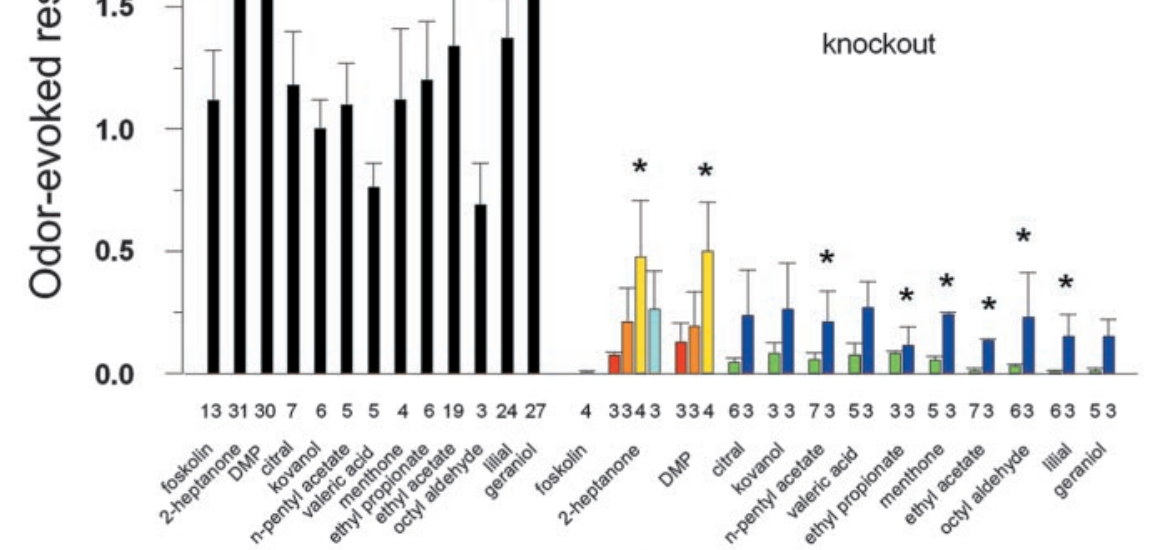

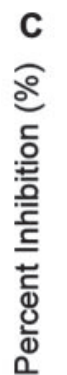
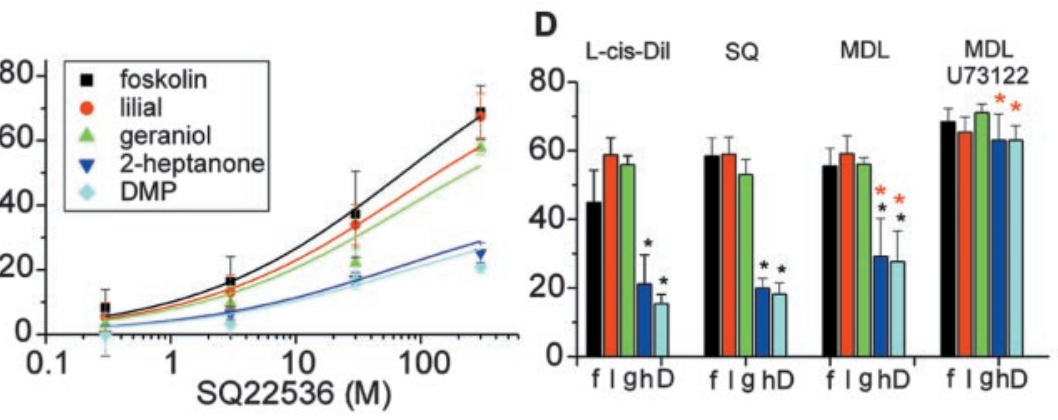

Figure 3. Odor-evoked EOG in adult CNGA2 knock-out and wild-type (WT) control mice and pharmacology in wild-type mice. $A$, Representative traces of EOG responses in wild-type and CNGA2 knock-out mice. Top, Responses to $100 \mu \mathrm{m}$ odorants and $1 \mu \mathrm{m}$ forskolin in wild-type mice ( $1 \mu \mathrm{m}$ is not a saturating concentration of forskolin). Wild-type mice responded to all odorants tested with relatively large changes in field potentials. Bottom, CNGA2 knock-out mice selectively responded to $100 \mu \mathrm{m}$ 2-heptanone and DMP but failed to respond or responded only weakly to other odorants at $500 \mu \mathrm{M}$. Application of Ringer's solution did not produce changes in field potential (control traces). Responses in wild-type and knock-out animals are presented in different scales. $B$, Average absolute value of the peak EOG responses to different concentrations of odor in CNGA2 knock-out mice (right panel) compared with the responses of wild-type mice at $100 \mu \mathrm{m}$ odor concentration (left panel). The number of mice tested is indicated under each bar. Those values that were significantly different from the EOG elicited by forskolin in CNGA2 knock-outs (i.e., significantly different from no response) are identified with an asterisk. C, Concentration dependence for percentage inhibition of EOG responses by the adenylyl cyclase inhibitor SQ22536 in wild-type mice. Mean \pm SEM $(n=5)$. Dose-response for forskolin was fit by a Hill equation with $\mathrm{EC}_{50}$ of $72 \mu \mathrm{m}$, a Hill coefficient of 0.5 , and a maximum percentage inhibition of $100 \%$. Dose-response curves for all other compounds were fit with a Hill equation using the same $\mathrm{EC}_{50}$ and Hill coefficient but 

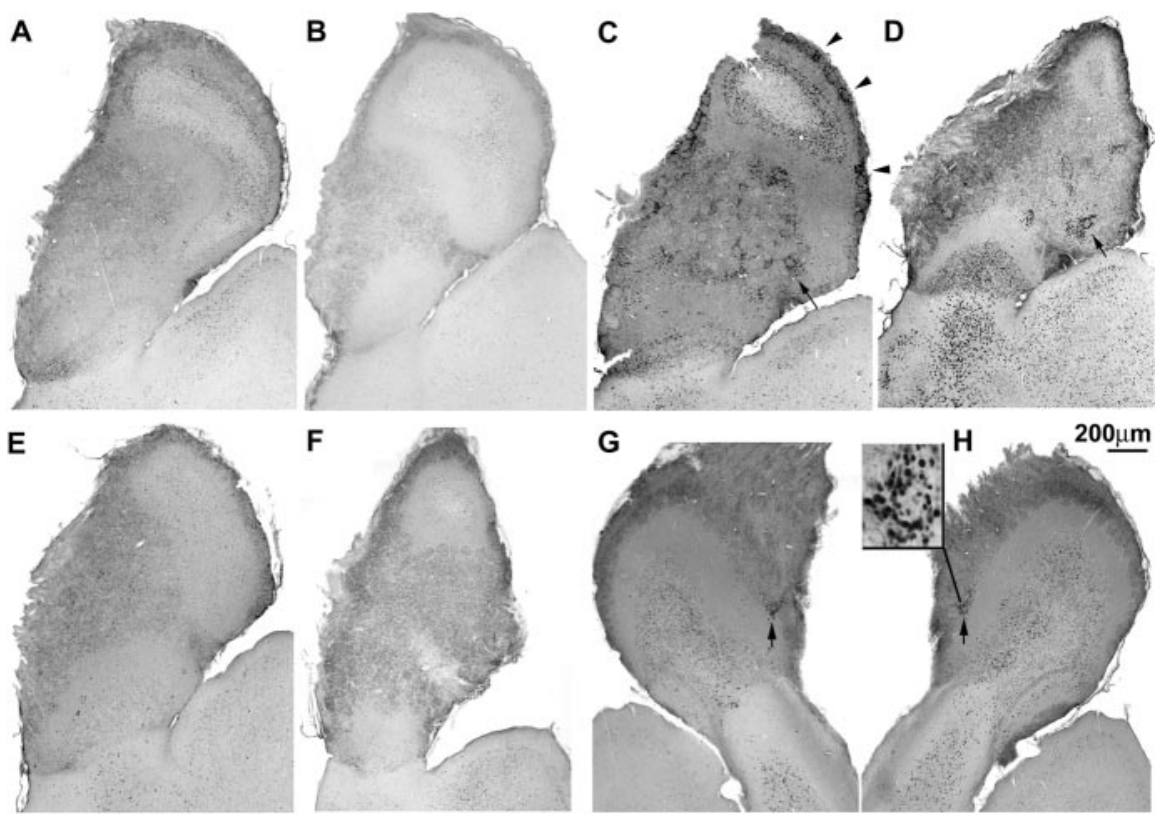

Figure 4. Odor-evoked Fos activity in the MOB of wild-type and CNGA2 knock-out mice. Light micrographs of Fos DAB reaction from representative sagittal sections. $A-D$ are sections from mice exposed to a mixture of 2 -heptanone and DMP $[(1 / 40) \times 0.5 \%$ each]. Micrographs are representative of three independent experiments for each condition. $A$, Sagittal section of bulb ipsilateral to naris occlusion in a wild-type mouse. Arrowheads indicate glomeruli that were active in $C$ but not $D$. Arrows indicate glomeruli activated in both $C$ and D. B, Section ipsilateral to naris occlusion in a CNGA2 knock-out mouse. $C$ and $D$ are sections of the bulb ipsilateral to naris that was not occluded. C, Wild-type. D, CNGA2 knock-out. E, CNGA2 knock-out exposed to fresh air (representative of 3 independent experiments). $F$, CNGA2 knock-out exposed to $(1 / 40) \times 1 \%$ lilial (representative of 2 independent experiments). $G, H$, CNGA2 knock-out exposed to (1/40) $\times 1 \%$ ethyl acetate (representative of 2 independent experiments). $G$, Left bulb. $H$, Right bulb.

\section{Select odorants elicit electro-olfactogram responses in CNGA2 knock-out mice}

To test whether the MOE responds to odorants detected by CNGA2 knock-out mice, we examined odor-evoked field potentials using EOG recordings (Fig. $3 A, B$ ). In agreement with previous studies (Brunet et al., 1996; Zhao and Reed, 2001), many odorants and $1 \mu \mathrm{M}$ forskolin failed to elicit any responses in CNGA2 knock-out mice. However, at higher concentrations (1-5 mM), most odorants induced small but reliable EOG responses (Fig. $3 B$ ). It is unclear whether responses at these high concentrations are second-messenger mediated. Two exceptions were the responses to DMP and 2-heptanone, which elicited field potential changes of moderate amplitude at $100 \mu \mathrm{M}$ as well as small but reproducible responses at much lower concentrations (down to $0.1 \mu \mathrm{M}$ ). Our results therefore indicate that a cAMP-

$\leftarrow$

with different maximum percentage inhibition: geraniol (77\%), lilial (86\%), 2-heptanone (43\%), and DMP (39\%). Solid lines, Curves for the best fit of the Hill equation to the data for the different odorants; black squares, forskolin; red circles, lilial; green triangles, geraniol; upside-down dark blue triangles, 2-heptanone; light blue diamonds, DMP. D, The CNG channel blocker L-cisdiltiazem (50 $\mu \mathrm{M})$ and the adenylyl cyclase inhibitors SQ22536 (300 $\mu \mathrm{M})$ and MDL-12330A (50 $\mu \mathrm{m})$ partially reduced odorant (100 $\mu \mathrm{M})$ - and forskolin (1 $\mu \mathrm{m}$ )-evoked responses in wild-type mice. Black, Forskolin; red, lilial; green, geraniol; dark blue, 2-heptanone; light blue, DMP. Note the differential effect on responses to 2-heptanone and DMP compared with forskolin, geraniol, and lilial. Number of experiments per condition is four for l-cis-diltiazem, 10 for SQ22536, and five to seven for MDL-12330A. For each drug, the percentage inhibition of the responses to forskolin, lilial, and geraniol was significantly larger than the percentage inhibition of the responses to 2-heptanone and DMP. Application of the PLC inhibitor U73122 (10 $\mu \mathrm{M})(D$, bars on right) produced further significant suppression of responses to 2-heptanone and DMP in the presence of MDL-12330A ( $50 \mu \mathrm{M})$. The preparation was preincubated with the inhibitors for $15 \mathrm{~min}$. Inhibition by the drugs was partially reversible (the percentage inhibition decreased by $50 \%$ after a 10 min wash with Ringer's). All responses used for comparison in a single animal were obtained strictly from the same recording position with one recording electrode. Black asterisks, DMP and 2-heptanone are significantly different from forskolin, geraniol, and lilial; red asterisks, suppression by U73122 + MDL-12330A on DMP and 2-heptanone was significantly different from the suppression by MDL-12330A alone. Ba ${ }^{2+}(5 \mathrm{~mm})$ abolished the EOG of all odors tested (data not shown). independent signaling pathway(s) contributes to EOG responses of 2-heptanone and DMP at micromolar concentrations and perhaps also to the responses of other odorants at higher concentrations $(>500$ $\mu \mathrm{M})$.

Additional evidence for responsiveness of the olfactory epithelium to 2-heptanone and DMP through cAMP-independent pathways comes from pharmacological blockade of odor-induced EOG changes in wild-type mice (Fig. 3C,D). We examined the effects of three cAMP pathway inhibitors on EOG responses to geraniol and lilial, odorants that could not be detected by CNGA2 knock-out mice, 2-heptanone and DMP, two odorants that could be detected by both strains, and forskolin (1 $\mu \mathrm{M})$ as positive control. We used SQ22536 and MDL12330A, two inhibitors of adenylyl cyclase type III that block ACIII with $\mathrm{ED}_{50}$ in the range of hundreds of micromolar (Onda et al., 2001). In addition, we used L-cis-diltiazem, which blocks the olfactory CNG channel (CNGA2/CNGA4/ CNGB1) (Frings et al., 1992). At the concentrations tested in Figure 3D, the drugs elicit $40-60 \%$ inhibition of forskolin, geraniol, and lilial responses in wild-type mice, consistent with their reported inhibitory potency. However, the responses to DMP and 2-heptanone were less sensitive to all inhibitors (Fig. 3C,D, dark and light blue bars and lines), consistent with the premise that both cAMP-dependent and noncAMP transduction pathway(s) contribute to the responses to MOE. As shown in Fig. 3D, in the presence of MDL12330A (5) $\mu \mathrm{M}), \mathrm{U} 73122(10 \mu \mathrm{M})$ further suppressed the responses to and 2-heptanone while there was little or no additiona inibition, compared with MDL12330A alone for forskolin, lilial, further block the EOG response to DMP and 2-heptanone, compared with MDL12330A alone. The percentage inhibition by L12330A $(50 \mu \mathrm{M})$ plus U73433 $(10 \mu \mathrm{M})$ was: forskolin (1 $\mu \mathrm{M}), 54.2 \pm$ 9.3; lilial $(100 \mu \mathrm{M}), 52 \pm 6.7$; geraniol $(100 \mu \mathrm{M})$, $44.5 \pm 5.9$; 2-heptanone $(100 \mu \mathrm{M}), 31.1 \pm$ 5.1; DMP $(100 \mu \mathrm{M}), 35.7 \pm 3$ (mean \pm SEM; $n=3)$. These data indicate that the PLC pathway is involved in detection of the putative pheromones DMP and 2-heptanone in the MOE.

\section{Odorants activate a small number of glomeruli in the main olfactory bulb of CNGA2 knock-out mice}

We reasoned that if detection of DMP, 2-heptanone, and ethyl acetate involves both the cAMP pathway as well as alternate transduction pathways in the MOE, exposure to these odorants would activate a smaller subset of glomeruli in CNGA2 knock-out mice compared with wild-type 
mice. Using an $\mathrm{Ab}$ against the Fos protein, an immediate early gene product that labels odor-activated juxtaglomerular neurons, we investigated the spatial activity pattern induced in the glomerular layer by a mixture of DMP and 2-heptanone (Fig. 4). Only low levels of Fos labeling were observed in wild-type and knock-out mice with ipisilateral naris occlusion (Fig. 4A,B) and mice exposed to clean air (Fig. $4 E$ ). In contrast, a small but distinct group of glomeruli was activated by the mixture of DMP and 2-heptanone in CNGA2 knock-out mice (Fig. 4D) $(27 \pm 4)$, and more glomeruli (Fig. 4C) $(92 \pm 8)$ were activated in wildtype mice (mean $\pm \mathrm{SEM} ; n=3$, each group). Interestingly, exposure of CNGA2 knock-out mice to $(1 / 40) \times 1 \%$ ethyl acetate elicited stimulation of three glomeruli per bulb found in locations distinct from those glomeruli activated by 2-heptanone and DMP (tested in two mice) (Fig. 4G,H). Activated glomeruli were located symmetrically in both right and left bulbs and were consistent among animals. The small number of glomeruli activated by ethyl acetate explains the lack of an EOG response for this odorant in CNGA2 knock-out mice (Fig. $3 A, B$ ), because responses from a small number of ORNs would be too small to differentiate from noise in an EOG measurement. Finally, we did not detect any activated glomeruli in CNGA2 knock-out mice stimulated with $(1 / 40) \times 1 \%$ lilial, an odorant that these mice did not detect behaviorally (two mice) (Fig. $4 F$ ). These data show that evoked activity in glomeruli of CNGA2 knock-out mice is odor specific.

To obtain information on the identity of the glomeruli activated by odorants in CNGA2 knock-out mice, we performed double-label experiments (Fig. 5). We identified the axons extended by ORNs expressing elements of the cAMP-signaling pathway by imaging GFP in mice where GFP was knocked in to replace CNGA2 (CNGA2-GFP knock-out mice) (Zhao and Reed, 2001). In addition, necklace glomeruli, a distinct subset of glomeruli whose receptor neurons express PDE2 but do not express elements of the cAMP-signaling pathway including CNGA2 (Juilfs et al., 1997), could be identified by PDE2 immunoreactivity. Figure 5, $A$ and $B$, shows the left and right bulbs of a CNGA2GFP knock-out mouse. GFP appears white, and Fos appears black in these micrographs. Fos-immunoreactive cells surrounded some GFP-positive (non-necklace) glomeruli; these glomeruli are located symmetrically in the left and right bulbs (Fig. $5 A, B$, arrows). Figure $5 C$ shows a high-magnification picture of a single GFP-positive glomerulus surrounded by numerous Fos-positive juxtaglomerular cells. In addition, in CNGA2 knock-out mice, Fos-positive cells sometimes surrounded PDE2positive glomeruli (Fig. 5D; red, PDE2; green, GFP; blue, Fos), indicating that some necklace glomeruli respond to the odor mixture. Some necklace glomeruli did not respond (data not shown).

\section{Naris occlusion abolishes residual tyrosine hydroxylase} expression in the glomerular layer of CNAG2 knock-out mice $\mathrm{TH}$ expression in juxtaglomerular cells is dependent on afferent input from the olfactory epithelium (Baker et al., 1993). In previous studies, both CNGA2 and ACIII knock-out mice showed a dramatic reduction in the expression of $\mathrm{TH}$ in the bulbs with residual high $\mathrm{TH}$ expression in the necklace glomeruli (Baker et al., 1999). We also found a significant reduction in TH immunoreactivity within the glomerular layer of CNGA2 knock-out mice, except that $\mathrm{TH}$ expression remained high in necklace glomeruli in CNGA2 knock-out mice and in juxtaglomerular cells of some non-necklace glomeruli, suggesting heterogeneity in the reduction of neural activity in juxtaglomerular cells (Fig. 6). Impor-
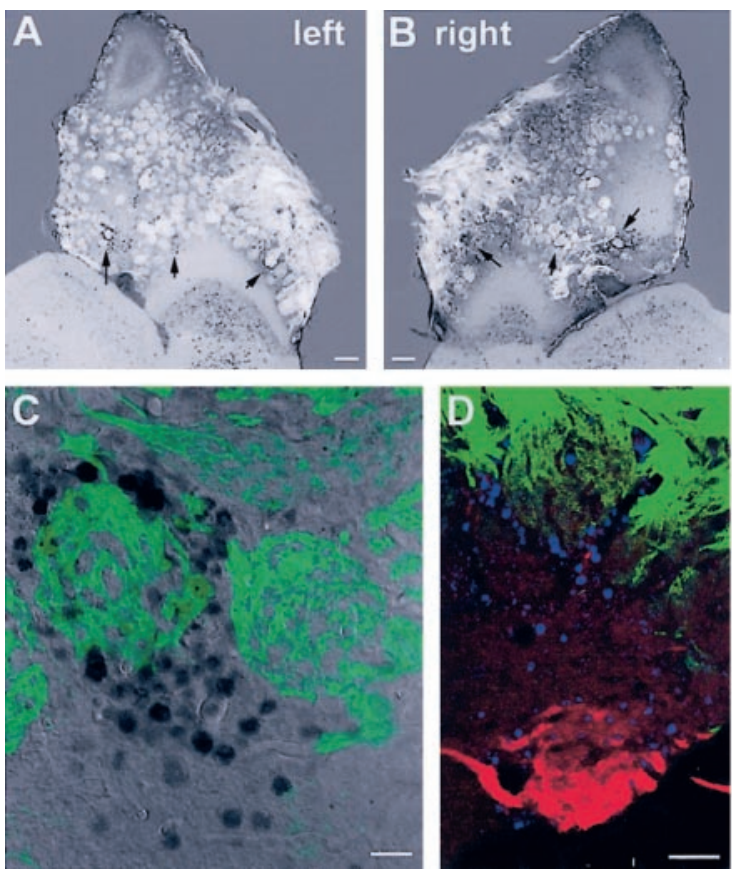

Figure 5. The mixture of $(1 / 40) \times 0.5 \%$ DMP and 2-heptanone activated both GFP-positive and PDE2-positive glomeruli in CNGA2-GFP knock-out mice. $A$ and $B$ are black and white micrographs showing Fos immunoreactivity (black nuclei surrounding glomeruli; arrows point to glomeruli) and GFP labeling denoting axons from ORNs that would express CNGA2 in wild-type mice (white). Odor-activated glomeruli are located symmetrically in the left $(A)$ and right $(B)$ bulbs (arrows). GFP fluorescence images were overlaid with transmission light microscopy images. Numerous distinct glomeruli are labeled by GFP, and some are surrounded by Fos-positive juxtaglomerular cells. C, A high-magnification confocal image showing a GFP-positive glomerulus (in green) surrounded by many Fos-labeled nuclei, indicating the glomerulus was activated by the odorant exposure. GFP (green channel) was overlayed on a Nomarski image. Fos reaction (DAB) appears as dark areas. D, A confocal micrograph showing two activated glomeruli surrounded by Fos-labeled nuclei (in blue). One of these glomeruli was GFP positive. The other was GFP negative but was positive for PDE2 Ab (in red), indicating this was a necklace glomerulus activated by DMP and 2-heptanone. The image was obtained from a medial section of the bulb. Scale bars: $A, B, 100 \mu \mathrm{m} ; C, D, 20 \mu \mathrm{m}$.

tantly, unilateral naris occlusion resulted in a dramatic reduction of TH immunoreactivity in necklace glomeruli in CNGA2 knockout mice. These results constitute independent evidence for participation of necklace glomeruli in odor detection in CNGA2 knock-out mice.

\section{Odors elicit elevation in Fos expression in the anterior olfactory nucleus and piriform cortex}

We also used odor-evoked Fos induction to examine activation of olfactory (piriform) cortex (Fig. 7). In response to $(1 / 40) \times 0.5 \%$ DMP and 2-heptanone, we observed Fos expression in a substantially larger number of cells in both the anterior olfactory nucleus $(\mathrm{AON})$ and piriform cortex in CNGA2 knock-out mice, compared with the same regions from mice exposed to fresh air (or naris occlusion; data not shown) (Fig. 7). This odor mixture also elicited a robust Fos signal in AON and piriform cortex in wildtype mice (data not shown).

\section{Discussion}

The data presented here conclusively show that odors detected by CNGA2 knock-out mice stimulate the MOS at peripheral and central levels. Therefore, our results are not in agreement with the premise that odor detection in the absence of a cAMP pathway is mediated exclusively by the vomeronasal system (Trinh and 

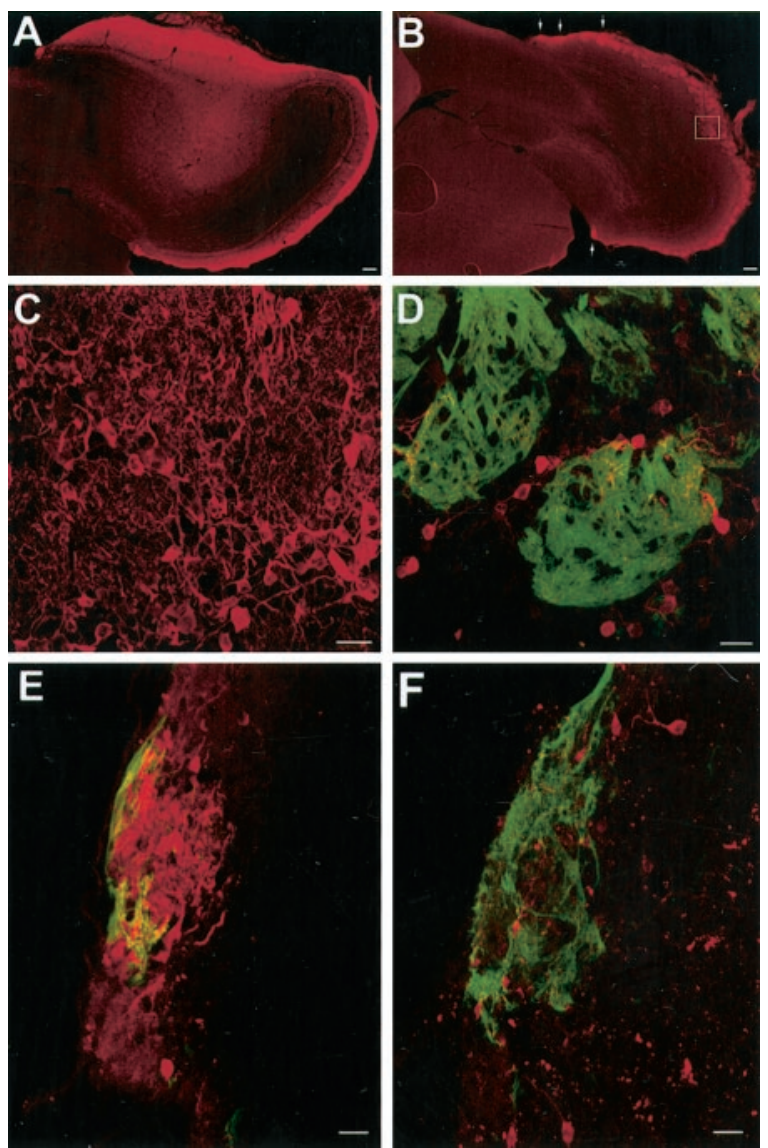

Figure 6. Tyrosine hydroxylase immonoreactivity. $A, B$, Low-magnification fluorescence micrographs. $A$, Wild-type. $B$, CNGA2-GFP knock-out. CNGA2 knock-out GFP mice showed general reduction in TH reactivity of regular glomeruli $(B)$ as compared with wild-type mice $(A)$. The TH immunoreactivity surrounding necklace glomeruli remained strong ( $B$, arrows). Highmagnification images show relatively uniform TH reactivity surrounding glomeruli of control mouse ( $C$ and heterogeneous reactivity in the knock-out mouse $(D)$. $C$ and $D$ are higher magnification florescence micrographs. $D$ was taken in the area shown in the box in $B$. Ipsilateral naris occlusion reduced $\mathrm{TH}$ activity $(F$, red) as compared with nonoccluded side $(E)$ in necklace glomeruli (positive for PDE2; green) from the same CNGA2 knock-out mouse. These two pictures were taken under the same excitation intensity and exposure conditions. Scale bars: $A, B, 100$ $\mu \mathrm{m} ;(-F, 20 \mu \mathrm{m}$. Data are representative of three independent experiments.

Storm, 2003). This conclusion primarily was based on experiments that used a potentially inadequate method to destroy the MOE (McBride et al., 2003) and ACIII knock-out mice. In ACIII knock-out mice, the elimination of the cAMP pathway is also associated with gross disarray of input to glomeruli from ORNs in the MOE (Trinh and Storm, 2003). However, we do not mean to imply that the VNO does not participate in odor detection in CNGA2 knock-out mice. As postulated by Trinh and Storm (2003), it is possible that the VNO also participates in detection of some odorants in CNGA2 knock-out mice. Whether the VNO participates in detection of vapor phase odorants in operant conditioning experiments remains to be determined.

Involvement of guanylyl cyclase D (GC-D) olfactory receptor neurons projecting to necklace glomeruli in response to odors in CNGA2 knock-out mice

On the basis of residual TH immunoreactivity, Baker et al. (1999) postulated that necklace glomeruli are active in CNGA2 knockout mice. Our findings that odors activate necklace glomeruli in CNGA2 knock-out mice (Fig. 5), and that TH activity in these glomeruli in CNGA2 knock-out mice could be reduced by ipsi-

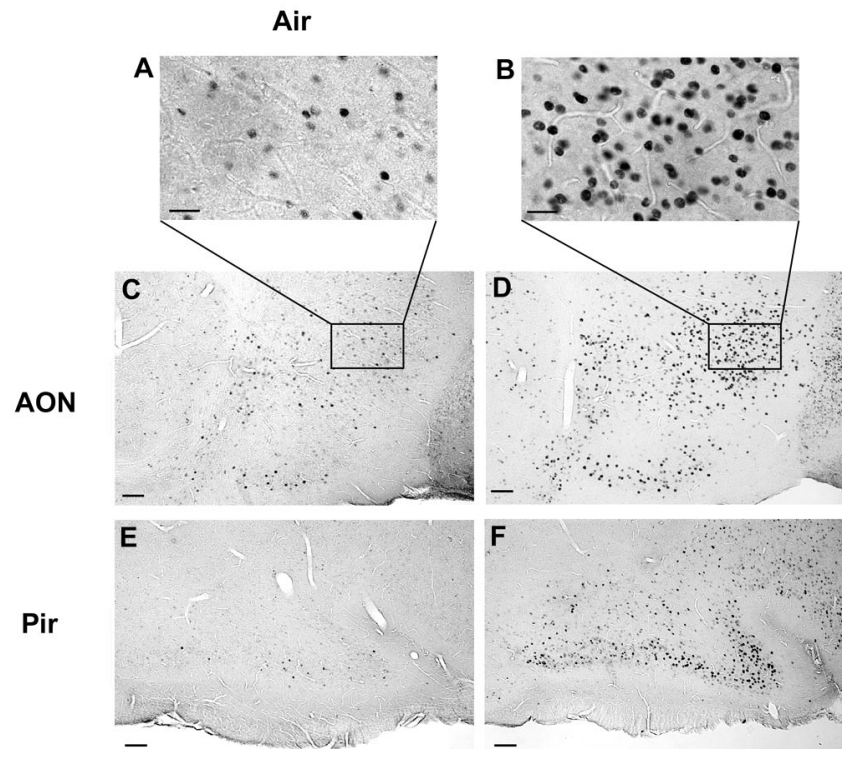

Figure 7. Fos immunoreactivity in $\mathrm{AON}(L=0.21-0.26 \mathrm{~mm}$; bregma $=1.5-2.2 \mathrm{~mm})(A$ and $B$ and lower magnification in $($ and $D)$ and piriform cortex (Pir; $L=1.36-1.39 \mathrm{~mm}$; bregma $=1.6-1.9 \mathrm{~mm})(E, F) \cdot A, C$, and $E$ are micrographs taken in a CNGA2 knock-out mouse exposed to fresh air, whereas $B, D$, and $F$ are micrographs from the same areas in a CNGA2 knock-out mouse exposed to $(1 / 40) \times 0.5 \%$ DMP and 2-heptanone. These micrographs are taken in $30 \mu \mathrm{m}$ brain slices cut sagittally. Scale bars: $A, B, 20 \mu \mathrm{m} ; C-F, 50 \mu \mathrm{m}$. Results are representative of three independent experiments.

lateral naris occlusion (Fig. 6), further substantiates the claim of Baker et al. (1999). Necklace glomeruli are of particular interest because they are a subset of "atypical" glomeruli that receive heavy cholinergic innervation and may have a role in motherinfant interaction (Greer et al., 1982). Necklace glomeruli are innervated by ORNs that do not express CNGA2 but, rather, express the cone subunit of the CNG channel (CNGA3) (Meyer et al., 2000). Thus, CNGA2 disruption would not be expected to affect their function. Activation of some necklace glomeruli by DMP and 2-heptanone (Fig. 5) indicates that necklace glomeruli participate in mediating responses of CNGA2 knock-out mice to these odorants.

\section{Involvement of non-GC-D olfactory receptor neurons in response to odors in CNGA2 knock-out mice}

Our data indicate that a subset of glomeruli, different from the necklace glomeruli, is also stimulated by putative pheromones in CNGA2 knock-out mice. Therefore, another signaling pathway distinct from the CAMP and cGMP pathways might be involved. A candidate signaling pathway would be odor-elicited stimulation of PLC (Schild and Restrepo, 1998; Spehr et al., 2002). In the $\mathrm{VNO}$, this pathway and downstream metabolites such as arachidonic acid and diacylglycerol have been implicated in stimulus transduction (Zufall and Munger, 2001; Dulac and Torello, 2003; Lucas et al., 2003), and the PLC signaling pathway appears to play an important role in olfactory responses in lobster and fish (Restrepo et al., 1990; Ache and Zhainazarov, 1995). Some evidence for this transduction pathway exists in human and rat ORNs (Rawson et al., 1997; Lischka et al., 1999; Kaur et al., 2001; Spehr et al., 2002) and, in the present study, we observed blockage by the PLC inhibitor U73122 on EOG responses to DMP and 2-heptanone. Involvement of this pathway in odor transduction in mice deserves additional inquiry. 


\section{Putative pheromones elicit responses in the main olfactory system in CNGA2 knock-out mice}

DMP and 2-heptanone have been postulated to be conspecific urinary chemosignals (Andreolini et al., 1987; Jemiolo et al., 1989). The excretion of these molecules into female mouse urine varies during the estrous cycle (Andreolini et al., 1987), and they participate in mediating effects such as inhibition or acceleration of puberty and extension of the estrous period in female mice (Jemiolo et al., 1989). DMP and 2-heptanone are detected at submicromolar concentrations by receptor neurons in the vomeronasal organ (Leinders-Zufall et al., 2000). Here, we show that these putative pheromones also stimulate the MOE and MOB in mouse. The fact that both the olfactory and vomeronasal organs detect putative pheromones is consistent with the detection of urine as a chemosignal by both systems (Restrepo et al., 2004). The partial inhibition of the EOG response of DMP and 2-heptanone by adenylyl cyclase and CNG channel inhibitors suggests that the responses to these compounds in the MOE are mediated by the cAMP pathway in only some ORNs and by an alternate signaling pathway, perhaps the GC-D, or PLC pathways in other ORNs. These results are consistent with a recent report that putative pheromones stimulate ORNs in the MOE and that antagonists of the cAMP pathway do not inhibit these responses (Leinders-Zufall et al., 2003).

\section{References}

Ache BW, Zhainazarov AB (1995) Dual second-messenger pathways in olfactory transduction. Curr Opin Neurobiol 5:461-466.

Andreolini F, Jemiolo B, Novotny M (1987) Dynamics of excretion of urinary chemosignals in the house mouse (Mus musculus) during the natural estrous cycle. Experientia 43:998-1002.

Baker H, Morel K, Stone DM, Maruniak JA (1993) Adult naris closure profoundly reduces tyrosine hydroxylase expression in mouse olfactory bulb. Brain Res 614:109-116.

Baker H, Cummings DM, Munger SD, Margolis JW, Franzen L, Reed RR, Margolis FL (1999) Targeted deletion of a cyclic nucleotide-gated channel subunit (OCNC1): biochemical and morphological consequences in adult mice. J Neurosci 19:9313-9321.

Belluscio L, Gold GH, Nemes A, Axel R (1998) Mice deficient for $\mathrm{G}_{\text {olf }}$ are anosmic. Neuron 20:69-81.

Bodyak N, Slotnick B (1999) Performance of mice in an automated olfactometer: odor detection, discrimination and odor memory. Chem Sens 24:637-645.

Brunet LJ, Gold GH, Ngai J (1996) General anosmia caused by a targeted disruption of the mouse olfactory cyclic nucleotide-gated cation channel. Neuron 17:681-693.

Cometto-Muniz JE, Cain WS, Abraham MH (2003) Quantification of chemical vapors in chemosensory research. Chem Sens 28:467-477.

DellaCorte C, Restrepo D, Menco BP, Andreini I, Kalinoski DL (1996) $G_{\alpha q}$ ' $\mathrm{G}_{\alpha 11}$ : immunolocalization in the neuroepithelium of the rat (Rattus rattus) and the channel catfish (Ictalurus punctatus). Neuroscience 74:261-273.

Dulac C, Torello AT (2003) Molecular detection of pheromone signals in mammals: from genes to behaviour. Nat Rev Neurosci 4:551-562.

Frings S, Lynch JW, Lindemann B (1992) Properties of cyclic nucleotidegated channels mediating olfactory transduction. Activation, selectivity, and blockage. J Gen Physiol 100:45-67.

Gold GH (1999) Controversial issues in vertebrate olfactory transduction. Annu Rev Physiol 61:857-871.

Greer CA, Stewart WB, Teicher MH, Shepherd GM (1982) Functional development of the olfactory bulb and a unique glomerular complex in the neonatal rat. J Neurosci 2:1744-1759.

Jemiolo B, Andreolini F, Xie TM, Wiesler D, Novotny M (1989) Puberty- affecting synthetic analogs of urinary chemosignals in the house mouse, Mus domesticus. Physiol Behav 46:293-298.

Juilfs DM, Fulle HJ, Zhao AZ, Houslay MD, Garbers DL, Beavo JA (1997) A subset of olfactory neurons that selectively express cGMP-stimulated phosphodiesterase (PDE2) and guanylyl cyclase-D define a unique olfactory signal transduction pathway. Proc Natl Acad Sci USA 94:3388-3395.

Kaur R, Zhu XO, Moorhouse AJ, Barry PH (2001) IP $_{3}$-gated channels and their occurrence relative to CNG channels in the soma and dendritic knob of rat olfactory receptor neurons. J Membr Biol 181:91-105.

Leinders-Zufall T, Lane AP, Puche AC, Ma WD, Novotny MV, Shipley MT, Zufall F (2000) Ultrasensitive pheromone detection by mammalian vomeronasal neurons. Nature 405:792-796.

Leinders-Zufall T, Ziesmann J, Puche AC, Bock R, Ma W, Novotny M, Zufall F (2003) Pheromone coding by the mammalian main olfactory epithelium. Chem Sens 28:A106.

Lischka FW, Zviman MM, Teeter JH, Restrepo D (1999) Characterization of Inositol-1,4,5-trisphosphate-gated channels in the plasma membrane of rat olfactory neurons. Biophys J 76:1410-1422.

Lucas P, Ukhanov K, Leinders-Zufall T, Zufall F (2003) A diacylglycerolgated cation channel in vomeronasal neuron dendrites is impaired in TRPC2 mutant mice: mechanism of pheromone transduction. Neuron 40:551-561.

Manzini I, Schild D (2003) cAMP-independent olfactory transduction of amino acids in Xenopus laevis tadpoles. J Physiol (Lond) 551:115-123.

McBride KM, Slotnick B, Margolis F (2003) Does intranasal application of zinc sulfate produce anosmia in mice? An olfactometric and anatomical study. Chem Sens 28:659-670.

Meyer MR, Angele A, Kremmer E, Kaupp UB, Müller F (2000) A cGMPsignaling pathway in a subset of olfactory sensory neurons. Proc Natl Acad Sci USA 97:10595-10600.

Onda T, Hashimoto Y, Nagai M, Kuramochi H, Saito S, Yamazaki H, Toya Y, Sakai I, Homcy CJ, Nishikawa K, Ishikawa Y (2001) Type-specific regulation of adenylyl cyclase. Selective pharmacological stimulation and inhibition of adenylyl cyclase isoforms. J Biol Chem 276:47785-47793.

Rawson NE, Gomez G, Cowart B, Brand JG, Lowry LD, Pribitkin EA, Restrepo D (1997) Selectivity and response characteristics of human olfactory neurons. J Neurophys 77:1606-1613.

Restrepo D, Miyamoto T, Bryant BP, Teeter JH (1990) Odor stimuli trigger influx of calcium into olfactory neurons of the channel catfish. Science 249:1166-1168.

Restrepo D, Arellano J, Oliva AM, Schaefer ML, Lin W (2004) Emerging views on the distinct, but related roles of the main an accessory olfactory systems in responsiveness to chemosensory signals in mice. Horm Behav, in press.

Schaefer ML, Young DA, Restrepo D (2001) Olfactory fingerprints for major histocompatibility complex-determined body odors. J Neurosci 21:2481-2487.

Schaper M (1993) Development of a database for sensory irritants and its use in establishing occupational exposure limits. Am Ind Hyg Assoc J 54:488-544.

Schild D, Restrepo D (1998) Transduction mechanisms in vertebrate olfactory receptor cells. Physiol Rev 78:429-466.

Setzer AK, Slotnick B (1998) Odor detection in rats with 3-methylindoleinduced reduction of sensory input. Physiol Behav 65:489-496.

Spehr M, Wetzel CH, Hatt H, Ache BW (2002) 3-Phosphoinositides modulate cyclic nucleotide signaling in olfactory receptor neurons. Neuron 33:731-739.

Trinh K, Storm DR (2003) Vomeronasal organ detects odorants in absence of signaling through main olfactory epithelium. Nat Neurosci 6:519-525.

Wong ST, Trinh K, Hacker B, Chan GC, Lowe G, Gaggar A, Xia Z, Gold GH, Storm DR (2000) Disruption of the type III adenylyl cyclase gene leads to peripheral and behavioral anosmia in transgenic mice. Neuron 27:487-497.

Zhao H, Reed RR (2001) X inactivation of the OCNC1 channel gene reveals a role for activity-dependent competition in the olfactory system. Cell 104:651-660.

Zufall F, Munger SD (2001) From odor and pheromone transduction to the organization of the sense of smell. Trends Neurosci 24:191-193. 